\section{REFERÊNCIAS}

AGUILAR, Maria José; ANDER-EGG, Ezequiel. Avaliação de serviços e programas sociais. Tradução de Jaime A. Clasen e Lúcia Mathilde E. Orth. Petropólis, RJ: Vozes, 1994.

ARRETCHE, Marta Tereza da Silva. Uma contribuição para fazermos uma avaliação menos ingênua. In: BARREIRA, Maria Cecília Roxo Nobre; CARVALHO, Maria do Carmo Brant de (Orgs.) Tendências e perspectivas na avaliação de políticas e programas sociais. São Paulo: IEE/ PUC/SP, 2001.

BRASIL. Constituição da República Federativa do Brasil. Brasília, DF, 1988. Disponivel em: <www. planalto.gov.br>. Acesso em: 1 nov. 2011.

Ministério da Educação. Plano Nacional de Assistência Estudantil. Brasília, DF, 2007.

Presidência da República. Decreto n 7.234 de 19 de julho de 2010. Dispõe sobre o Programa Nacional de Assistência Estudantil. Brasília, DF, 2010.

DRAIBE, Sônia Miriam. Avaliação de implementação: esboço de uma metodologia de trabalho em políticas públicas. In: BARREIRA, Maria Cecília Roxo Nobre; CARVALHO, Maria do Carmo Brant de (Orgs.) Tendências e perspectivas na avaliação de políticas e programas sociais. São Paulo: IEE/ PUC/SP, 2001.

FÓRUM DE ASSUNTOS COMUNITÁRIOS E ESTUDANTIS. Plano Nacional de Assistência Estudantil. Brasília, DF, 2007.

FRIGOTTO, Gaudêncio. Projeto societário, ensino médio integrado e educação profissional: o paradoxo da falta e sobra de jovens qualificados. Rio de Janeiro, 2009. Disponível em: <http://www. diaadia.pr.gov.br/det/arquivos/File/GRUPO\%20 DE\%20ESTUDOS/2009/CURSOSTECNICOS/ texto1-GaudencioFrigotto.pdf>. Acesso em: 1 nov. 2011

INSTITUTO FEDERAL DE EDUCAÇÃO, CIÊNCIA E TECNOLOGIA DO MARANHÃO. Plano de Desenvolvimento Institucional: 2009-2013. São Luís, 2009.

INSTITUTO Federal de Educação, Ciência e Tecnologia: concepção e diretrizes. Ministério da Educação. Brasília, DF: MEC, 2008.

MORAES, Michele Rodrigues de; LIMA, Gleyce Figueiredo de. Assistencialização das políticas educacionais brasileiras. In: ENCONTRO BRASILEIRO DE EDUCAÇÃO E MARXISMO: marxismo, educação e emancipação humana, 5., 2011, Florianópolis. Anais... Florianópolis, abr. 2011.
PEREIRA, Potyara A. P. Como conjugar especificidade e intersetorialidade na concepção e implementação da política de assistência social. Serviço Social \& Sociedade, São Paulo, ano 25, n. 77, p. 54-62, mar. 2004.

Necessidades humanas: subsídios à crítica dos mínimos sociais. São Paulo: Cortez, 2000.

RAICHELIS, Raquel. Gestão pública e a questão social na grande cidade. Lua Nova, São Paulo, n. 69 , p. 13-14, 2006.

SILVA, Maria Ozanira da Silva e. Avaliação de políticas e programas sociais: uma reflexão sobre o conteúdo teórico e metodológico da pesquisa avaliativa. In: SILVA, Maria Ozanira da Silva et al. Pesquisa avaliativa: aspectos teóricometodológicos. São Paulo: Veras; São Luís: Grupo de Avaliação e Estudo da Pobreza e de Políticas Direcionadas à Pobreza, 2008.

\section{Edna Maria Coimbra de Abreu}

Assistente Social

Mestrado em Políticas Públicas pela Universidade Federal do Maranhão (UFMA)

Instituto Federal de Educação, Ciência e Tecnologia do Maranhão

E-mail: edmari85@hotmail.com

Universidade Federal do Maranhão (UFMA)

Cidade Universitária, Av. dos Portugueses, 1966, Baganga - São Luís - MA

CEP: $65080-805$ 


\title{
AVALIAÇÃO DOS IMPACTOS DO PROGRAMA DE REFORMA AGRÁRIA ENTRE OS AGRICULTORES DO ESTADO DO CEARÁ
}

\author{
Germano Silva Maia \\ Universidade Federal do Ceará (UFC)
}

\author{
Ahmad Saeed Khan \\ Universidade Federal do Ceará (UFC)
}

Patrícia Verônica Pinheiro Sales Lima

Universidade Federal do Ceará (UFC)

\begin{abstract}
AVALIAÇÃO DOS IMPACTOS DO PROGRAMA DE REFORMA AGRÁRIA ENTRE OS AGRICULTORES DO ESTADO DO CEARÁ

Resumo: O objetivo desse trabalho é avaliar a experiência do programa de reforma agrária - Projetos de Assentamentos do INCRA entre os agricultores do Estado do Ceará. A fim de capturar os impactos desse programa sobre o comportamento dos beneficiados, em relação aos que não foram beneficiados, aplicou-se o método propensity score matching. Os resultados apontam a não efetividade do programa em gerar impactos significativos na qualidade de vida, desenvolvimento ambiental, desenvolvimento político institucional para seus beneficiários.
\end{abstract}

Palavras-chave: Escore de propensão, assentamentos rurais, desenvolvimento rural.

IMPACTS EVALUATION OF THE REFORM AGRARIAN PROGRAM AMONG FARMERS FROM STATE OF CEARÁ Abstract: The objective of this paper is to evaluate the experience of Agrarian Reform Program - Settlement Projects of INCRA at the state of Ceará. The method Propensity Score Matching was applied, with the purpose of to capture the effects of program on the behavior of benefited in relation to those which were not benefited. The results showed at not effectiveness of the program in generating significant impacts in life quality, environmental development, institutional politic development the beneficiaries when compared to those who are not contemplated by the program.

Key words: Propensity score, land settlements, rural development. 


\section{INTRODUÇÃO}

A reforma agrária é um dos mais polêmicos, controversos e complicados temas a serem analisados, avaliados e superados no Brasil. Nele, as opiniões são tão distintas quanto plurais. Elas vão desde a convicção na extrema necessidade de uma ampla e profunda reforma agrária - sem a qual nunca se poderá falar em justiça social e desenvolvimento neste País - à condenação da fragilidade das instituições nacionais, incapazes sequer de garantir o "sagrado" direito à propriedade privada.

No Ceará, a luta pela conquista da terra remonta o início do século XX e é simbolicamente representada pela figura do beato José Lourenço e pelas manifestações ocorridas no Sítio Caldeirão, em 1928. Desde então, busca-se a realização de uma ampla Reforma Agrária e a adoção de políticas agrícolas e sociais voltadas para o fortalecimento e a expansão da agricultura familiar. Dentre tais intervenções, são exemplos emblemáticos no Estado, o Programa Cédula da Terra e o Programa de Reforma Agrária do Governo Federal (Projetos de Assentamentos)

Essas iniciativas, em seu escopo, não representariam apenas a distribuição de terras improdutivas, mas formas ou programas de combate à pobreza e à exclusão social. No entanto, apesar de ser apontado como um Estado de vanguarda quando se trata de intervenções associadas à reforma agrária no Brasil, o Ceará ainda hoje convive com a concentração dos meios de produção e as precárias condições de acesso à terra no meio rural.

O histórico de luta por igualdade no campo, as cifras direcionadas aos Programas de Reforma Agrária paraaaquisição deterras, bemcomoas verbas complementares, conduzem a uma expectativa de que, ao visitar um assentamento, o investigador se deparará com pequenos núcleos dinâmicos e em acelerado processo de desenvolvimento. Porém, ao contrário, ao se ter acesso a alguns assentamentos de reforma agrária - isso depois de se constatar a grande dificuldade de acesso à grande maioria deles - o cenário observado instiga questionamentos nas mais diversas perspectivas: qualidade de vida, capital social, desenvolvimento ambiental e político-institucional. A reforma agrária tem assumido papel estratégico como base para um novo desenvolvimento sustentável rural?

Partindo-se desta inquietação pretende-se avaliar neste artigo o Programa de Reforma Agrária Projetos de Assentamentos no Estado do Ceará, um programa de reforma agrária do governo federal sob responsabilidade do Instituto Nacional de Colonização e Reforma Agrária (INCRA).

$O$ texto encontra-se organizado em três partes além desta introdução. $\mathrm{Na}$ primeira são apresentados os aspectos metodológicos adotados no estudo com destaque para o método Propensity Score Matching, suas vantagens e limitações na avaliação de políticas públicas. Em seguida são discutidos os impactos do programa e, por fim, são colocadas algumas considerações sobre o papel do programa no desenvolvimento rural sustentável.

\section{MÉTODO PROPENSITY SCORE MATCHING E SUA UTILIZAÇÃO NA AVALIAÇÃO DO PROGRAMA DE REFORMA AGRÁRIA PROJETOS DE ASSENTAMENTOS DO INCRA}

A avaliação de políticas públicas embora já reconhecida como uma sub-área da Ciência Política possui uma trajetória recente. Os Estados Unidos foram os pioneiros nos estudos sobre políticas públicas a partir de 1950. Em seguida, por volta de 1970, a Europa iniciou pesquisas nesse campo. No Brasil a preocupação em avaliar as intervenções governamentais é bem mais recente e alcançou seu boom na década de 1980 (TREVISAN; VAN BELLEN, 2008).

Segundo Cunha (2006) o interesse dos governos por pesquisas avaliativas concentra-se na necessidade de identificar efetividade, eficiência, accountability e desempenho da gestão pública. Como argumentam Ala-Harja e Helgason (2000), as metas de uma avaliação de políticas públicas são a otimização do processo de tomada decisão, (maximizar resultados e minimizar erros), uma melhor alocação dos recursos públicos e uma prestação de contas à sociedade. Assim, em concordância com Bardach (2000) a avaliação de políticas públicas é, atualmente, uma atividade política e social.

No Brasil diferentes argumentos podem justificar avaliações de políticas públicas: a modernização das instituições governamentais que requer uma gama de informações para as funções de planejamento e gestão, a necessidade de uma agenda de desenvolvimento que contemple as desigualdades regionais e locais, a maior eficiência na aplicação de recursos públicos.

Admitindo-se tais argumentos como incontestes, torna-se premente a criação de meios capazes de auferir a eficiência, a eficácia ea efetividade das políticas públicas. Nesta perspectiva existe um esforço conjunto de instituições particulares de pesquisa, meio acadêmico e órgãos governamentais buscando desenvolver procedimentos metodológicos que restrinjam vieses provocados por: inexistência de informações relativas às condições socioeconômicas dos beneficiários antes da implementação da política/ programa; ausência de um grupo controle composto por indivíduos não beneficiários de modo a favorecer uma análise comparativa e/ou mudanças na condição de vida de beneficiários decorrentes do "passar do tempo" e não da política/programa em avaliação.

Os vieses citados são bastante perceptíveis em avaliações de políticas ou programas sociais. No âmbito das políticas de promoção social, mais especificamente aquelas direcionadas ao desenvolvimento rural, ressalta-se ainda o fato 
de grande parte da população ser beneficiária simultaneamente de mais de uma política ou programa. No meio rural é comum uma família ser simultaneamente beneficiária do PRONAF, de Projeto de Assentamento do INCRA e de programas de transferência de renda como o Bolsa Família. Em casos dessa natureza o desenho da avaliação de uma política específica deveria "filtrar" os prováveis impactos de outras intervenções governamentais. Uma proposta metodológica que reduz este viés é o método Propensity Score Matching.

A aplicação do método Propensity Score Matching na avaliação do Programa de Reforma Agrária - Projetos de Assentamentos do INCRA consistiu em duas etapas: estimação de um modelo LOGIT e em seguida a formação dos pares de beneficiários e não beneficiários com escore de propensão o mais semelhante possível.

O modelo Logit foi estimado com o objetivo de calcular a probabilidade (escore de propensão) de cada entrevistado ser beneficiado pelo programa. Foi adotada como variável dependente a dummy Grupo em que o valor 1 foi atribuído aos beneficiários do programa e o valor zero aos não beneficiários. A especificação do modelo, isto é, a escolha das variáveis, ocorreu após tentativas, até que a hipótese de equilíbrio entre as variáveis do modelo foi satisfeita ${ }^{1}$. Segundo Resende e Oliveira (2008) um maior de número de variáveis contribui para um pareamento mais eficiente, pois quanto maior o número de características observáveis utilizadas, mais similaridades serão encontradas entre os indivíduos dos grupos de tratamento e controle. O Quadro 1 apresenta as variáveis adotadas na estimação do modelo logit usado na obtenção do escore de propensão usado no pareamento.

A segunda etapa do método consistiu no pareamento ou formação dos pares de beneficiários e não beneficiários que possuem escore de propensão o mais semelhante possível, o que possibilita a análise dos impactos do programa. Dentre os métodos de pareamento foi adotado o método do vizinho mais próximo (Nearest Neighbour Matching ).

Assim:

$$
V(i)=\min _{j}\left\|p_{i}-p_{j}\right\|, i \in B(1)
$$

Sendo:

$V(i)=$ conjunto de observações do grupo de controle a serem relacionadas com o indivíduo i do grupo de tratamento.

$p_{i}$ e $p_{j}=$ significam as probabilidades de fazer parte do programa.

Quadro 1 - Variáveis componentes do modelo logit e sua operacionalização $\mathrm{B}=$ grupo dos beneficiários.

\begin{tabular}{|c|c|c|}
\hline Variável & Classificação da Variável & Operacionalização \\
\hline Grupo & Variável dummy & $\begin{array}{l}0 \text { - Não beneficiários } \\
1 \text { - Beneficiários }\end{array}$ \\
\hline Anos de Estudo & Escalar & \\
\hline Idade & Escalar & \\
\hline Total de Indivíduos na Residência & Escalar & \\
\hline Renda Não Agrícola & Escalar & \\
\hline Quantidade de Bens Duráveis & Escalar & \\
\hline É convidado a Participar das Reuniões & Variável dummy & $\begin{array}{l}0 \text { - Não } \\
1 \text { - Sim }\end{array}$ \\
\hline $\begin{array}{l}\text { Opinião quanto à existência de Solidariedade entre } \\
\text { os Membros da Comunidade }\end{array}$ & Variável dummy & $\begin{array}{l}0 \text { - Não } \\
1 \text { - Sim }\end{array}$ \\
\hline Participação nas Eleições dos Líderes da Associação & Variável dummy & $\begin{array}{l}0 \text { - Não } \\
1 \text { - Sim }\end{array}$ \\
\hline Assistência Técnica & Variável dummy & $\begin{array}{l}0 \text { - Não } \\
1 \text { - Sim }\end{array}$ \\
\hline Participação em Curso de Capacitação & Variável dummy & $\begin{array}{l}0 \text { - Não } \\
1 \text { - Sim }\end{array}$ \\
\hline
\end{tabular}

Fonte: Elaboração própria.

O pareamento consiste em ordenar os indivíduos do grupo de tratamento e controle em pares com características semelhantes, sendo cada par formado por um indivíduo de cada grupo. Segundo Barcellos (2004) esta metodologia procura, para cada observação tratada, a observação de controle com o escore de propensão mais próximo, que por sua vez pode ser feita com ou sem reposição; 
respectivamente, o conjunto de indivíduos do grupo controle pareados com os indivíduos do grupo de tratamento é dado por:

$$
C(i)=\min j|| p_{i}-p_{j}||
$$

Admitindo que $C$ (i) pode ser calculado com e sem reposição. Quando a reposição é permitida significa que um mesmo indivíduo do grupo controle pode ser pareado com mais de um indivíduo do grupo de tratamento. No estudo adotou-se a reposição ou repetição.

A vantagem de adotar a repetição conforme Oliveira e outros (2007) pode ser resumida em três pontos: 1) maior facilidade de interpretação dos resultados, uma vez que a magnitude dos diferenciais encontrados pode variar entre as técnicas; 2) utilização do maior número possível de observações do tratamento uma vez a amostra do grupo controle pode ser menor que a de tratamento.

Para a estimação do método é necessário indicar até quantos vizinhos mais próximos devem ser considerados. No estudo adotou-se três vizinhos, ou seja, o cálculo do ATT (Average Treatment effect on Treated) foi realizado com os três vizinhos mais próximos. Os valores dos ATTs foram calculados a partir da diferença entre os valores médios que resultam do pareamento. O ATT é uma estimativa do impacto médio do Programa sobre os seus beneficiários. A sua obtenção é feita por meio da diferença média da variável resposta ${ }^{2}$ dos pares (tratado e controle). Os ATT's apresentam-se com sinais negativos ou positivos, indicando o provável impacto do programa na variável resultado analisada.

O efeito médio do programa sobre o indivíduo do grupo de tratamento (ATT) foi dado pela seguinte expressão:

$$
\begin{gathered}
\text { ATT }=E\{E[Y 1 i \mid D i=1, p(X i)]-E[Y o i \mid D i=0, \\
p(X i)] \mid D i=1\}
\end{gathered}
$$

o primeiro termo foi estimado por meio do grupo de tratamento e o segundo termo por meio do resultado médio do grupo controle $(e m p(X))$.

$\mathrm{Na}$ mensuração dos impactos foram selecionadas variáveis resposta as quais buscaram mensurar o impacto do programa em aspectos subjetivos como qualidade de vida, capital social, desenvolvimento ambiental e desenvolvimento político-institucional das famílias beneficiárias. A operacionalização destas variáveis foi feita por meio de índices agregados e encontra-se descrita no Apêndice $A$.

A validação da estimativa dos ATTs foi feita a partir de procedimento de estatística inferencial, mais especificamente o procedimento bootstrapping que baseia-se em uma amostragem repetida com reposição ou replicação que permite a obtenção de erro padrão do estimador (no caso o ATT) e a verificação dos impactos significativos do programa avaliado. Neste estudo, para cada estimativa de ATT foram realizadas 50 replicações.

A aplicação do método Propensity Score Matching foi feita no programa STATA v.9, comandos psmatch2.
A área de interesse para o estudo foi a microrregião do Baixo Jaguaribe, no Estado do Ceará. Sua escolha é devida à existência de um número considerável de assentamentos vinculados ao Programa em estudo. Os municípios selecionados foram Russas, Tabuleiro do Norte, Morada Nova e Ibicuitinga.

Os dados foram obtidos a partir da aplicação de questionários a dois grupos de entrevistados: agricultores beneficiários do Programa (tratamento) e agricultores não proprietários e não assentados (controle ou contrafactual). A amostra foi selecionada de maneira não aleatória. Ela foi assim determinada para atender a um pressuposto do método Propensity Score Matching, o qual reforça a necessidade de que os grupos tratamento e controle sejam os mais semelhantes possíveis.

A unidade amostral foi definida em termos de $n$ famílias do grupo de tratamento e $m$ famílias do grupo de controle. Dentre as várias metodologias testadas para definir o tamanho da amostra, todas apresentaram tamanhos não compatíveis com as condições e os recursos disponíveis para a execução do estudo. Por essa razão, optou-se por determinar uma amostra que fosse, aproximadamente, 10\% do tamanho do grupo de beneficiários, obtendo-se assim a amostra do grupo de tratamento. A amostra do grupo de controle foi igual ao tamanho do grupo de tratamento acrescida de $40 \%$. Portanto, entrevistouse 50 famílias beneficiárias do programa do Incra e 70 famílias de produtores não beneficiários.

\section{A AVALIAÇÃO DO IMPACTO DO PROGRAMA DE REFORMA AGRÁRIA: projeto de assentamentos do INCRA}

A necessidade de uma reforma agrária que se sobreponha ao discurso político persiste desde o Brasil colônia, época da formação dos primeiros latifúndios. No decorrer de tão longo período o direcionamento de intervenções governamentais com o objetivo de distribuição mais justa de terras vem ocorrendo de diferentes formas e intensidade, tornando-se mais visível a partir da década de 1950 com a industrialização e a intensificação de processos de urbanização. Em pleno século $X X I$ a concretização do que o próprio governo caracteriza como reforma agrária no Estatuto da Terra (Lei n 4504 , de 300 de novembro de 1964) é uma utopia na maior parte do território rural brasileiro. Como é recorrente nos textos sobre reforma agrária no Brasil, a questão não é apenas a distribuição de terras, mas a criação de infraestrutura mínima que garanta a permanência do pequeno agricultor no campo com uma qualidade de vida digna. Os números oficiais divulgam elevados recursos públicos investidos nesse sentido, no entanto, não são perceptíveis os resultados sociais da reforma agrária, o que instiga a elaboração de estudos como o apresentado a seguir: "A AVALIAÇÃO DO IMPACTO DO PROGRAMA DE REFORMA AGRÁRIA: projeto de assentamentos do INCRA". 
3.1 Breve contextualização do programa de reforma agrária: projetos de assentamentos do INCRA

A ideia central da reforma agrária está associada ao direcionamento de ações públicas voltadas para a redistribuição de terras privadas que não cumprem o seu papel social. Segundo Lima e outros (2011), com essa redistribuição busca-se a democratização da estrutura fundiária.

No Brasil a busca de uma reforma agrária remonta à época da colonização. Mais recentemente (desde a década de 1990) dois principais programas, com formatação distinta, foram experimentados: - Reforma Agrária Solidária/Cédula da Terra e o Projeto de Assentamentos do INCRA executado pelo Instituto Nacional de Colonização e Reforma Agrária (INCRA). A distinção mais marcante entre os dois é a forma de obtenção da terra por parte do beneficiário.

No Programa Cédula da Terra o acesso à terra se dá mediante negociação em um mercado de terras. A política adota como pressuposto a existência de um fundo de terras para financiar a compra e a venda de terra entre proprietários dispostos a vendê-las e camponeses sem terra ou com pouca terra, interessados em adquiri-las (OLIVEIRA, 2006). No Projeto de Assentamentos do INCRA os recursos utilizados na aquisição das terras não são reembolsados, ou seja, a terra é doada e os recursos aportados são $100 \%$ a fundo perdido.

Dada a importância social da reforma agrária no Brasil, a avaliação de ambos os programas já foi objeto de estudo de vários pesquisadores e sob diferentes procedimentos metodológicos. Como destaque citam-se a avaliação do Programa Cédula da Terra realizada por Buainain e outros (2003), bem como os estudos de Sparovek (2003) sobre a qualidade dos assentamentos rurais brasileiros e de Heredia e outros (2004) sobre os impactos dos assentamentosno meio rural brasileiro.

Nesta seção apresenta-se uma análise dos impactos do programa de reforma agrária Projeto de Assentamentos no Estado do Ceará a partir do emprego do método Propensity Score Matching.

O programa de reforma agrária Projeto de Assentamentos foi criado e reconhecido pelo Programa Nacional de Reforma Agrária (PNRA) e está sob a jurisdição e atuação das superintendências regionais do INCRA. Segundo dados do Ministério do Desenvolvimento Agrário (MDA), até 2011 o programa implementou 8.865 projetos, beneficiando 1.235 .130 famílias $\mathrm{e}$ distribuindo 87.559.858,95 ha. No Ceará, área geográfica deste estudo, foram 33.564 famílias assentadas em 896.231,99 ha.

Em consonância com a Política Nacional de Reforma Agrária, a qual aponta em suas diretrizes que os projetos de assentamentos devem ser implementados de tal modo a promover o desenvolvimento territorial, assume-se neste artigo que assentamentos rurais sustentáveis guardam estreita relação com reforma agrária. Deste modo, são plausíveis questionamentos inerentes aos efeitos da reforma agrária (via projetos de assentamentos) nas múltiplas dimensões de sustentabilidade: socioeconomia (determinante da qualidade de vida), ambiental e político institucional. Tais dimensões envolvem diferentes aspectos quantificáveis ou não. Essa natureza multidimensional nem sempre mensurável foi considerada na avaliação dos efeitos do programa de reforma agrária Projeto de Assentamentos o que motivou o emprego de índices sintéticos representando a qualidade de vida, o capital social, os níveis de desenvolvimento ambiental e político institucional dos grupos tratamento e controle. Ressalta-se que o uso de agregação de indicadores é de grande utilidade na avaliação de políticas públicas.

\subsection{Os impactos do programa de reforma} agrária: projeto de assentamentos do INCRA

Antes da apresentação dos resultados obtidos com a aplicação do método Propensity Score Matching será apresentada uma análise comparativa dos beneficiários e não beneficiários por meio de procedimentos de estatística descritiva e inferencial, a fim de apresentar particularidades dos dois grupos. Como se observa na Tabela 1 , o fato de pertencer a um beneficiário do Programa não pode ser apontado como causa de mudança na qualidade de vida, no desenvolvimento ambiental ou políticoinstitucional nas propriedades rurais, haja vista que não foi constatada diferença significativa entre os dois grupos (beneficiários e não beneficiários) quanto aos três aspectos citados.

Considerando-se a qualidade de vida, sabese que melhorar as condições de saúde e educação dos beneficiários não é objetivo direto do Programa. No entanto, a privação desses e de outros serviços compromete o capital humano necessário para a plena capacidade produtiva do morador rural. No contexto da reforma agrária e do Programa do INCRA torna-se um entrave para a maximização dos resultados esperados. A carência de infraestrutura básica nos assentamentos visitados, especialmente acesso à água tratada, esgotamento ou escoadouro sanitário e serviço de coleta de lixo foi apontada como principais fatores limitantes de uma melhor qualidade de vida. É observável a ausência, por parte dos planejadores e executores do Programa, de uma preocupação com a criação de infraestrutura básica como forma de potencializar os resultados dos investimentos em produção. Ainda não foi incorporada a ideia de que investir em infraestrutura básica ultrapassa a simples oferta de serviços para as famílias rurais, sendo um requisito para o sucesso de diferentes atividades econômicas geradoras de emprego e renda. 
A avaliação dos indicadores de desenvolvimento ambiental ressalta uma preocupante realidade constatada nas propriedades rurais: o uso irracional dos recursos naturais, principal matéria prima do setor primário. Dentre os índices calculados o pior desempenho foi verificado no Índice de Desenvolvimento Ambiental. Os assentados não adotam práticas de conservação, não costumam fazer análise do solo ou calagem. A impressão é a de que os entrevistados estão completamente alheios à importância dos cuidados com os recursos naturais como forma de zelar pela sobrevivência no médio e longo prazo. Quando alguns entrevistados foram questionados sobre o porquê de não adotarem cuidados com o meio ambiente, muitos responderam que entendem a importância, porém, tratam-na com descaso, priorizando outros fatores, como uma maior produção. As terras distribuídas pelo Programa apresentam-se em sua maioria, com problemas de fertilidade o que, aliada à baixa capacidade de gestão empresarial, carência de recursos financeiros e falta de assistência técnica, leva os produtores ao uso intensivo da solo, uso exacerbado de agroquímicos e adoção de práticas agrícolas agressivas ao ambiente como as queimadas.

Quanto ao desenvolvimento Político Institucional, a falta de assistência técnica ou o apoio governamental é uma das principais reclamações entre os entrevistados, sejam eles não beneficiários ou beneficiários do Programa. No caso destes últimos, a reforma agrária nos moldes definidos pelo Programa do INCRA não tem conseguido levar aos assentados os produtos/serviços necessários para torná-los mais competitivos.

$\mathrm{Na}$ comparação dos beneficiários e não beneficiários quanto aos quatro aspectos analisados, os resultados mostraram diferença estatisticamente significativa apenas no nível de capital social.

Tabela 1 - Valores médios dos índices de qualidade de vida, capital social, desenvolvimento ambiental e desenvolvimento político institucional de beneficiários e não beneficiários do programa de reforma agrária: Projeto de Assentamentos do INCRA

\begin{tabular}{|c|c|c|}
\hline Indicador & Beneficiários & Não beneficiários \\
\hline Índice de Qualidade de Vida & 0,6245 & 0,6891 \\
\hline Testes & Estatística do teste & Significância \\
\hline Levene (igualdade de variâncias) & 2,295 & 0,142 \\
\hline $\begin{array}{l}\text { T de Student (comparação de } \\
\text { médias) }\end{array}$ & $-0,605$ & 0,551 \\
\hline Classificação & $\begin{array}{c}\text { Médio nível de } \\
\text { qualidade de vida }\end{array}$ & $\begin{array}{c}\text { Médio nível de } \\
\text { qualidade de vida }\end{array}$ \\
\hline Índice de Capital Social & 0,691 & 0,347 \\
\hline Testes & Estatística do teste & Significância \\
\hline Levene & 0,482 & 0,493 \\
\hline T de Student & 4,384 & 0,000 \\
\hline Classificação & Médio nível de capital social & Baixo nível de capital social \\
\hline Índice de Desenvolvimento ambiental & 0,411 & 0,408 \\
\hline Testes & Estatística do teste & Significância \\
\hline Levene & 0,000 & 1,000 \\
\hline T de Student & 0,030 & 0,980 \\
\hline Classificação & $\begin{array}{c}\text { Baixo nível de } \\
\text { desenvolvimento ambiental }\end{array}$ & $\begin{array}{c}\text { Baixo nível de } \\
\text { desenvolvimento ambiental }\end{array}$ \\
\hline $\begin{array}{l}\text { Índice de Desenvolvimento Político } \\
\text { Institucional }\end{array}$ & 0,615 & 0,557 \\
\hline Testes & Estatística do teste & Significância \\
\hline Levene & 0,008 & 0,933 \\
\hline T de Student & 0,330 & 0,752 \\
\hline Classificação & $\begin{array}{l}\text { Médio nível de desenvolvimento } \\
\text { político institucional }\end{array}$ & $\begin{array}{l}\text { Médio nível de desenvolvimento } \\
\text { político institucional }\end{array}$ \\
\hline
\end{tabular}

Fonte: Resultados da pesquisa.

Ressalta-se que, apesar das inúmeras constatações de desconfiança, suspeitas de gestões fraudulentas por parte de alguns dirigentes de associações etc., é absolutamente esperado que os beneficiários possuam índice de capital social superior aos não beneficiários. Isso porque, para se tornarem beneficiários, eles já tiveram que demonstrar um nível de coordenação e associação considerável.

Os resultados obtidos pela simples comparação dos grupos beneficiários e não beneficiários do programa apresentam o viés discutido anteriormente referente a diferenças entre 
os indivíduos dos dois grupos além do fato de não pertencerem ao programa avaliado. Os resultados apresentados a seguir apresentam a vantagem proposta pelo método Propensity Score Matching de redução dessa limitação.

Conforme descrito anteriormente, o método Propensity Score Matching é dividido em duas etapas. A primeira é realizada com a estimação de um modelo Logit que visa a aferir a probabilidade de cada entrevistado ser beneficiário do programa de assentamento em questão. Como resultado dessa etapa, é obtido o escore de propensão, uma nova variável que reflete a probabilidade de cada indivíduo ser beneficiário do programa. Na segunda etapa, ocorrerá a formação dos pares de beneficiários e não beneficiários cujas probabilidades calculadas, na fase anterior, mais se aproximam. É aqui que será feita a análise dos impactos.

A escolha do modelo Logit ocorreu após várias tentativas, com um conjunto de noventa e duas variáveis, e levou em consideração cinco critérios, cujos valores obtidos no modelo estimado são apresentados em parênteses: a) Valor da função de verossimilhança (log likelihood $=-35,1791)$; b) Valor do critério AIC $(0,776)$; c) Valor do critério BIC $(-445,787)$; d) Valor do pseudo R2 $(0,5655)$ e e) $\%$ de casos corretamente classificados $(88,24 \%)$.

O objetivo foi buscar o melhor pareamento entre beneficiários e não beneficiários e a redução do viés de seleção comum em estudos de avaliação de políticas públicas. Os valores dos critérios 1, 2 e 3 devem ser os menores possíveis, ao passo que os valores dos critérios 4 e 5 devem ser os maiores possíveis. Os critérios 1, 2 e 3 apresentam valores bem pequenos, como é desejável. Com base no Pseudo R2, é possível afirmar que o modelo apresenta $56,55 \%$ de ajuste. Também é possível afirmar que $88,24 \%$ dos casos foram corretamente classificados. Portanto, pode-se afirmar que se trata de um modelo bem ajustado.

A Tabela 2 apresenta as variáveis selecionadas para a estimação do modelo Logit. "Quantidade de Bens Duráveis", "Participação nas Eleições dos Líderes da Associação", "Participação em Curso de Capacitação", entre outras, não selecionam os grupos de forma significativa, uma vez que seus respectivos níveis de significância encontram-se acima de 0,05 (5\%) o que confere alta probabilidade de erro ao rejeitar a hipótese de que os coeficientes estimados sejam iguais a zero. Em outras palavras, elas não contribuem significativamente com o objetivo do modelo, que é o de separar ou destacar características que sejam decisivas para determinar a participação de um indivíduo no programa. As variáveis "Anos de Estudo", "Ser Convidado a Participar das Reuniões" e "Assistência Técnica" selecionam os grupos de forma significativa.

Tabela 2 - Resultado do Modelo de Regressão Logit entre beneficiários e não beneficiários do programa de reforma agrária: Projeto de Assentamentos do INCRA

\begin{tabular}{l|c|c|c|c}
\hline \multicolumn{1}{c|}{ Variável } & $\begin{array}{c}\text { Odds } \\
\text { Ratio }\end{array}$ & $\begin{array}{c}\text { Erro } \\
\text { padrão }\end{array}$ & Estatística Z & Significância \\
\hline Anos de Estudo & 0,8263 & 0,0639 & $-2,47$ & 0,014 \\
\hline Idade & 0,9578 & 0,0267 & $-1,54$ & 0,123 \\
\hline Total de Indivíduos na Residência & 1,2627 & 0,2443 & 1,21 & 0,228 \\
\hline Renda Não Agrícola & 0,9962 & 0,0019 & $-1,92$ & 0,055 \\
\hline Quantidade de Bens Duráveis & 1,2626 & 0,4381 & 0,67 & 0,501 \\
\hline Convite para participação de reuniões na associação & 32,3179 & 54,8341 & 2,05 & 0,041 \\
\hline Opinião quanto à existência de Solidariedade entre os & 0,1298 & 0,1462 & $-1,81$ & 0,07 \\
\hline Membros da Comunidade & 3,2672 & 4,7629 & 0,81 & 0,417 \\
\hline Participação nas Eleições dos Líderes da Associação & 22,7499 & 24,5625 & 2,89 & 0,004 \\
\hline Assistência Técnica & 1,5568 & 1,0822 & 0,64 & 0,524 \\
\hline Participação em Curso de Capacitação & & & & 0 \\
\hline
\end{tabular}

Fonte: Resultados da pesquisa

O ODDS RATIO mede a variação do logaritmo natural da relação das probabilidades de ocorrência ou não de um evento. De outra maneira, ele compara indivíduos beneficiários e não beneficiários apenas com base na variável de interesse, considerando constantes as demais variáveis do modelo. Toma-se, a exemplo, a variável "Opinião quanto à existência de Solidariedade entre os Membros da Comunidade". Com base em seu Odds Ratio, pode-se afirmar que o fato de existir ou não essa solidariedade entre os membros da comunidade reduz suas chances 
Índice de Capital Social, Índice de Desenvolvimento Ambiental e Índice Político Institucional.

Considerando os resultados dos ATT's, Tabela 3, pode-se afirmar que existe o indicativo de piora na qualidade de vida, no desenvolvimento ambiental, nas relações político institucionais. Já com relação ao capital social, pode-se afirmar que existe um indicativo de melhora ou vantagem para os beneficiários.

Esses resultados são bastante semelhantes aos resultados obtidos diretamente pelos índices calculados sem o pareamento, discutidos anteriormente. Dado que os valores dos ATT's são apenas estimativas, para validá-los, faz-se necessário que se proceda ao teste bootstrapping, identificando assim os ATT's realmente significativos. Pelos dados da Tabela 4, pode-se afirmar que, de fato, nenhuma das estimativas de ATT foi validada pelo teste, a um nível de significância de 5\%. No entanto, tomando apenas o indicativo apontado pelo sinal das estimativas de ATT's, o programa só contribuiria positivamente com a formação de capital social.

O fato de não terem sido verificados impactos significativos do Programa de Reforma Agrária e, ainda, existir uma tendência negativa de tais impactos pode estar associado ao nível de pobreza prevalecente nos assentamentos. Pobreza essa ainda à espera de instrumentos de combate adequados.

Embora as análises pareadas e não pareadas demonstrem resultados bastante semelhantes e apontem uma conclusão desfavorável para o programa de assentamento desenvolvido pelo INCRA, a viabilidade desse programa precisa ser analisada, também, por outras abordagens.

Tabela 3 - Estimativas de impacto do programa de reforma agrária: Projeto de Assentamentos do INCRA pelo Método Propensity Score Matching

\begin{tabular}{l|r|r|r|r|r}
\hline \multicolumn{1}{c|}{ Variável Resposta } & $\begin{array}{c}\text { Valores médios } \\
\text { Beneficiários }\end{array}$ & $\begin{array}{c}\text { Valores } \\
\text { médios Não } \\
\text { Beneficiários }\end{array}$ & $\begin{array}{c}\text { ATT } \\
\text { Dife- } \\
\text { rença }\end{array}$ & $\begin{array}{c}\text { Erro } \\
\text { padrão }\end{array}$ & Estatística t \\
\hline $\begin{array}{l}\text { Índice de Qualidade de } \\
\text { Vida }\end{array}$ & 0,6245 & 0,6320 & $-0,0074$ & 0,0346 & $-0,21$ \\
\hline Índice de Capital Social & 0,6899 & 0,6475 & 0,0042 & 0,0061 & 0,69 \\
\hline $\begin{array}{l}\text { Índice de } \\
\begin{array}{l}\text { Desenvolvimento } \\
\text { Ambiental }\end{array}\end{array}$ & 0,4107 & 0,4401 & $-0,0029$ & 0,0019 & $-1,58$ \\
\hline $\begin{array}{l}\text { Índice de } \\
\text { Desenvolvimento } \\
\text { Político-Institucional }\end{array}$ & 0,6150 & 0,8320 & $-0,2170$ & 0,1294 & $-1,68$ \\
\hline
\end{tabular}

Fonte: Resultados da pesquisa.

Tabela 4 - Resultado do teste de hipótese para as estimativas de ATT utilizando o Bootstrapping

\begin{tabular}{l|r|r|r|r}
\hline \multicolumn{1}{c|}{ Variável Resposta } & $\begin{array}{c}\text { Coeficiente obser- } \\
\text { vado }\end{array}$ & $\begin{array}{c}\text { Erro Padrão - } \\
\text { Bootstrapping }\end{array}$ & Z & Significância \\
\hline Índice de Qualidade de Vida & $-0,0074$ & 0,0267 & $-0,28$ & 0,782 \\
\hline Índice de Capital Social & 0,0424 & 0,0619 & 0,69 & 0,493 \\
\hline Índice de Desenvolvimento Ambiental & $-0,0294$ & 0,0196 & $-1,50$ & 0,134 \\
\hline $\begin{array}{l}\text { Índice de Desenvolvimento Político- } \\
\text { Institucional }\end{array}$ & $-0,0217$ & 0,1209 & $-1,79$ & 0,073 \\
\hline
\end{tabular}

Fonte: Resultados da pesquisa.

Para uma análise mais detalhada de cada índice, tomando-se o de qualidade de vida como o primeiro, nota-se que dentre os quatorze indicadores que compõe esse índice, três apresentam resultados graves dentro desses assentamentos. São eles: "Forma de Adquirir Medicamentos", "Tratar a Água de beber" e "Destino dado ao lixo". Com relação à forma de obtenção de medicamentos, $66 \%$ dos entrevistados afirmam só terem acesso a medicamentos fornecidos pelo Estado e com dificuldade. Dentre esses, $34 \%$ afirmam não ter acesso de maneira alguma.
A maioria desses assentamentos não possui água dentro dos seus limites. O por si só limita qualquer intenção de elevados níveis de produção. Nos demais casos, o melhor cenário é a existência de pequenas cisternas, que acumulam o mínimo suficiente para o consumo humano durante o período não chuvoso. Isso ocorre em cerca de $60 \%$ dos casos, tornando quase impossivel manter produções ou animais em períodos fora dos meses de chuva. Efetivamente, não existe o hábito de tratar a água de beber, sendo $74 \%$ dos casos. Quanto ao destino do lixo, 90\% afirmam descartar nas superfícies, ruas ou queimar. 
Quanto ao índice de capital social, como já relatado, não há nada de relevante no resultado expresso, que não reflete mais que uma précondição para conseguirem o benefício do programa. Ressalta-se em relação a isso que o impacto social do Programa em termos de fortalecimento das associações é pequeno. Não se verifica nos assentamentos criados a existência de associações com alta capacidade de representar os interesses da comunidade, de identificar as prioridades locais ou de cobrar maior efetividade das políticas públicas.

Com relação ao índice de desenvolvimento ambiental, dos quatorze indicadores que 0 compõem, três apresentam resultados alarmantes: "Qual método de controle de pragas", "Quantos tipos de agrotóxicos são utilizados" e "Realiza queimadas em suas atividades". Com relação ao primeiro indicador, $74 \%$ dos entrevistados afirmam fazer uso de agrotóxicos como principal meio de combate às pragas. Com relação ao segundo, $74 \%$ dos entrevistados beneficiários afirmam usar pelo menos um tipo de agrotóxico. Por fim, com relação ao terceiro indicador, $64 \%$ dos entrevistados afirmam fazer queimadas. Portanto, existe uma baixíssima consciência, por parte dos beneficiários, em preservar suas terras, que já são de baixa qualidade.

Sobre o índice político institucional $80 \%$ dos entrevistados afirmam não terem recebido quaisquer produtos ou serviços das Secretarias de Agricultura do Estado e do Município. Existe pouca presença dessas esferas públicas na oferta de produtos ou serviços. E quando há a oferta, é de produtos e serviços de baixa qualidade em termos de eficiência, frequência etc., além de não cobrirem a totalidade das famílias necessitadas.

De um modo geral, o cenário observado nos assentamentos implementados pelo Programa de Reforma Agrária do INCRA no Ceará é de alta vulnerabilidade com elevados riscos econômicos. Além dos problemas naturais existentes no meio rural do Estado, caso dos períodos de estiagens, do tipo de solo, das elevadas taxas de evapotranspiração, observa-se, ainda, a falta de infraestrutura para escoamento da produção e a descapitalização dos beneficiários. As condições verificadas impedem a produção em grande escala, o enfrentamento das forças de mercado enfim, a competitividade dos assentados.

Um importante fator que não foi abordado nesse estudo - mas que veio a tomar destaque durante a pesquisa de campo - foi a questão da localização espacial desses assentamentos e suas possibilidades de escoamento da produção. É objeto de estudo o quanto a questão da localização tem figurado como um importante fator de competitividade e atração de investimentos. Especialmente nesse ponto, afirma-se, com contundência, frente ao vivenciado durante a pesquisa, que esses pequenos produtores familiares poderiam estar produzindo semicondutores - ao invés de bens primários de baixa elasticidade preço da demanda - e, ainda assim, não seriam competitivos. Isso se deve às localizações péssimas - e condições de acesso ainda piores - da maioria desses assentamentos.

Outro fator de difícil mensuração que esse estudo deixou de abordar - mas que possui uma dimensão humana tão forte e tão decisiva, capaz inclusive de relativizar completamente os resultados desse estudo - é a satisfação verificada em cada trabalhador rural beneficiado com seu pedacinho de terra. Fato verificado diante da expressão, à sua maneira: "Pode ser o que for, mas essa terra aqui eu posso chamar de minha [...]".

\section{CONCLUSÃO}

O método Propensity Score Matching mostrou-se adequado à avaliação dos impactos do do programa de reforma agrária: Projeto de Assentamentos do INCRA, confirmou os resultados obtidos por meio do procedimentos de estatística inferencial e, principalmente, as impressões obtidas "in loco" durante a pesquisa de campo.

A partir da análise sem pareamento das amostras, por meio de estatística inferencial, os beneficiários dos programas de assentamento só apresentam vantagem significativa, em relação aos não beneficiários, no aspecto Capital Social. Esse resultado foi corroborado, em parte, pelo Propensity Score Matching, já que, por meio dos ATT's e teste bootstrapping não foi observada diferença significativa entre os grupos quanto aoo Índice de Capital Social.

Apesar dos resultados, com e sem pareamento, conduzirem a conclusões que, em suma, justificariam a não continuidade do programa, outros aspectos precisam ser considerados nessa análise. Eles vão desde a compreensão de que a análise técnica aqui desenvolvida é reducionista e constituída de diversas limitações a outras tantas de caráter altamente subjetivo. Porém, é perceptível que o programa precisa passar por reformulação em seus fundamentos, sob risco de nunca alcançar o objetivo de melhora de qualidade de vida dos assentados. Essas reformas devem passar pelo critério de escolha das propriedades, pelas pessoas a serem beneficiadas, pela localização, pelos valores limitados ao número de famílias, pela fiscalização das relações entre diretores das associações e representantes dos programas, por um estudo que vise a incluir, no bojo dos programas, outras políticas públicas; pela forma de assistência técnica, pelo estabelecimento de um critério de infraestrutura mínima e por diversos outros fatores. Sem as reformas a que se refere o parágrafo anterior, não será apenas a melhora na qualidade de vida que não será alcançada. Na realidade, nenhum dos aspectos tratados no presente estudo será atingido. Inclusive e principalmente, a sustentabilidade dos programas. 


\section{REFERÊNCIAS}

ALA-HARJA, M.; HELGASON, S. Em direção às melhores práticas de avaliação. Revista do Serviço Público, Brasília, DF, ano 51, n. 4, out./dez., 2000.

BARCELLOS, S. H. M. F. S. L. Efeitos da tributação sobre organização e localização de firmas no setor de serviços. 68 f. 2004. Dissertação (Mestrado em Economia) - Pontifícia Universidade Católica do Rio de Janeiro, Rio de Janeiro. 2004.

BARDACH, E. A practical guide for policy analysis: the eightfold path to more effective problem solving. New York: Seven Bridges Press, 2000.

BUAINAIN, A. M. et al. Estudo de avaliação de impactos do Programa Cédula da Terra: relatório preliminar - Setembro-IE/Unicamp-Banco Mundial. [S.I.], 2003. Relatório de pesquisa.

CUNHA, C. G.S. da. Avaliação de políticas públicas e programas governamentais: tendências recentes e experiências no Brasil. Rio Grande do Sul: Secretaria de Coordenação e Planejamento, 2006. Disponível em:<www.ufpa.br/epdir/images/ docs/paper06.pdf> . Acesso em: 13 jan. 2013.

HEREDIA, B. et al. Impactos dos assentamentos: um estudo sobre o meio rural brasileiro. Brasília, DF: Instituto Interamericano de Cooperação para Agricultura-Núcleo de Estudos Agrários e Desenvolvimento Rural; São Paulo: Unesp, 2004.

Lima, P. V. P. S. et al. Políticas públicas e desenvolvimento sustentável: a realidade dos assentamentos de reforma agrária no Ceará. Revista de Políticas Públicas, São Luís, v. 15, n. 1, P. 85-97, jan./jun. 2011.

OLIVEIRA, A. M. de. A política de contra reforma agrária do Banco Mundial no Ceará. Revista GEOUSP: Espaço e Tempo, São Paulo, n. 19, p. 151-175, 2006.

V.H. Crescimento econômico e equidade social nos municípios do Ceará: uma evidência empírica entre 1991 e 2000. Fortaleza: IPECE, 2006.

RESENDE, A. C. C.; OlIVEIRA, A. M. H. C. de. Avaliando resultados de um programa de transferência de renda: o impacto do Bolsa-Escola sobre os gastos das famílias brasileiras. Estudos econômicos, São Paulo, v. 38, n. 2, p. 235-265, abr./jun. 2008.

SPAROVEK, G. (Coord.). A qualidade dos Assentamentos de Reforma Agrária Brasileira. 2003 USP/MDA/FAO., 204 p.

TREVISAN, A. P.; VAN BELLEN, H. M. Avaliação de políticas públicas: uma revisão teórica de um campo em construção. Revista Brasileira de Administração Pública, Salvador, v. 42, p. 529550, 2008.

Notas

A hipótese de equilíbrio é satisfeita quando os valores médios das variáveis não diferem entre os grupos de tratamento e controle, no caso, beneficiários e não beneficiários.

2 Variável resposta é aquela em que se deseja verificar o impacto do projeto.

\section{APÊNDICE A - Operacionalização das variáveis resposta}

A quantificação dos aspectos relativos à qualidade de vida, capital social, desenvolvimento ambiental e desenvolvimento político-institucional das foi realizada por meio da construção de índices agregados. Segundo Neiva (2000), matematicamente, pode-se definir esses índices da seguinte forma:

$$
I(L)=\frac{1}{S} C_{k=1}^{s}
$$

Sendo:

$L=$ aspecto analisado (Qualidade de Vida; Capital Social; Desenvolvimento Ambiental ou Desenvolvimento Político Institucional)

$$
C_{k}=\frac{1}{M} \sum_{i=1}^{m}\left[\frac{1}{n} \sum_{i=1}^{n}\left(\frac{E_{i j}}{E_{\max i}}\right)\right]
$$

Sendo:

I $L$ = Índice $L$

$\mathrm{C}_{k}=$ Contribuição do indicador "k" no índice $L$;

$E_{k}^{k}=$ Escore da $i$-ésima variável do indicador "k" obtido do j-ésimo produtor;

$E_{\max i}=$ Escore máximo da i-ésima variável do indicador "k";

$i=1, \ldots \ldots \ldots \ldots \ldots, n$ (variáveis que compõem o indicador "k");

$j=1, \ldots \ldots \ldots \ldots \ldots, m$ (entrevistados);

$k=1, \ldots \ldots \ldots \ldots \ldots, s$ (indicadores que compõem $o$ índice $L$ ).

Ainda segundo Neiva (2000), impõe-se a seguinte parametrização quanto ao nível do índice $L$ :

De $0 £ I(L) £ 0,5$; tem-se um baixo nível de $L$.

De $0,5<I(L) £ 0,8$; tem-se um médio nível de $L$.

De $0,8<I(L) £ 1$; tem-se um alto nível de $L$.

Abaixo, são apresentados os indicadores que compuseram cada índice, bem como as respectivas variáveis e escores presentes em cada indicador.

a) Indicadores de Qualidade de Vida - (IQV) (composto pelas dimensões: saúde, educação, habitação, saneamento e higiene, bens duráveis e lazer) 


\section{DIMENSÃO SAÚDE}

IQV 1. Como costuma ser atendido quando você e/ou sua família necessita de serviços de saúde?

0 - Completa ausência de serviços de saúde; 1 - Atendimento por agente de saúde.

2 - Posto de saúde com serviços básicos; 3 Hospital da rede pública/privada.

IQV 2. Em caso de doença na família, como costuma adquirir os medicamentos para o tratamento?

0 - Não compra porque não tem renda e nem tem acesso aos fornecidos pelo governo.

1 - Tem acesso aos do governo com dificuldade; 2 - Tem acesso aos do governo sem dificuldade.

\section{DIMENSÃO EDUCAÇÃO}

IQV 3. Existem escolas na comunidade ou próximo? 0 - Não; 1 - De ensino fundamental (até a quinta série); 2 - De ensino fundamental (até a nona série);

3 - De ensino médio.

IQV 4. Os Filhos recebem material do Governo? I_l Sim I_ Não

IQV 5. Como você tem acesso às informações?0 Não tem Acesso; 1 - Através de rádio/tv.

\section{DIMENSÃO HABITAÇÃO}

IQV 6. Qual a forma de cessão de uso da residência? 0 - Alugada; 1 - Cedida; 2 - Própria.

IQV 7. Qual o tipo de construção do domicílio? 0 - Casa de taipa; 1 - Casa de tijolo; 2- Casa de tijolo, reboco; 3 - Casa de tijolo, reboco e piso cerâmica;

4 - Casa de tijolo, forrada, reboco e piso cerâmica.

IQV 8. Qual o tipo de energia utilizada na residência?

0 - Não tem energia elétrica; 1 - Tem Energia elétrica.

\section{DIMENSÃO DO SANEAMENTO E HIGIENE}

IQV 9. Qual a Forma de acesso à água? 0 - Carro pipa; 1 - Rio/açude; 2 - Poço/ cacimba/cisterna; 3 - Água encanada

IQV 10. Que água para beber é utilizada no domicílio?

0 - Água sem tratamento; 1 - Água com tratamento (filtrada, fervida, com cloro).

IQV 11. Que destino é dado ao lixo do domicílio?

0 - Lixo jogado nas ruas, canais, superfícies, queimado; 1 - Lixo enterrado;

2 - Lixo é recolhido por carros da prefeitura.

IQV 12. Qual o tipo de escoadouro do banheiro ou sanitário?

3 - Esgoto; 2 - Fossa séptica; 1 - Fossa rudimentar; 0 - Vala ou céu aberto.

\section{DIMENSÃO DOS BENS DURÁVEIS}

IQV 13. Quais destes bens você possui?

( ) Geladeira ( ) TV ( ) Moto ou carro ( ) Bicicleta ( ) Fogão a gás ( ) Antena parabólica ( ) Som ( ) Liquidificador

\section{DIMENSÃO DO LAZER}

IQV 14. Quais destas opções de lazer você possui? 0 - Nenhuma infraestrutura de lazer; 1 Campo de futebol; 2 - Campo de fut., clubes ou festas populares/religiosas.

b) Indicadores de Capital Social - (ICS)

ICS 1. As pessoas sempre se preocupam mais com o bem-estar próprio e de seus familiares do que da comunidade.

0 - Sim 1 - Não

ICS 2. Que grau de influência você acredita ter para fazer de sua comunidade um lugar melhor para viver

( 0 )Nenhum ( 1 ) Pouco ( 2) Muito.

ICS 3. O senhor é convidado a participar das reuniões/assembleias da associação? 0 - Não 1 - Sim

ICS 4. $O(a)$ senhor(a) frequenta as reuniões da associação?

0 - Não 1 - Sim

ICS 5. Todas as questões levantadas nas reuniões são respondidas?

0 - Não 1 - Sim

ICS 6. O(a) senhor(a) participa da escolha dos líderes da associação?

0 - Não 1 - Sim

ICS 7. As decisões são aprovadas em reuniões/ assembleias?

0 - Não 1 - Sim

ICS 8. Nas reuniões o(a) senhor(a) apresenta sugestões?

0 - Não 1 - Sim

ICS 9. As decisões tomadas são realmente postas em prática ou adotadas? 0 - Não 1 - Sim

ICS 10. Os líderes da associação prestam contas aos associados? 0 - Não 1 - Sim

ICS 11. $O(a)$ senhor(a) contribui com cotas ou taxas?

0 - Não 1 - Sim

ICS 12. O(a) senhor(a) participa de eventos organizados pela associação?

0 - Não 1 - Sim

ICS 13. Se o(a) senhor(a) tiver um problema, sempre aparecerá alguém da comunidade para ajudar?

0 - Não 1 - Sim

ICS 14. O senhor(a) está satisfeito(a) com o processo de escolha de seus dirigentes? 0 - Não 1 - Sim 
ICS 15. O(a) senhor(a) confia na maioria dos membros da comunidade ou sócios da associação?

0 - Não 1 - Sim

ICS 16. O(a) senhor(a) confia nos líderes da comunidade ou na maioria da diretoria da associação?

0 - Não 1 - Sim

ICS 17. O(a) senhor(a) acredita em sua capacidade de contribuir para solucionar os problemas da sua comunidade? 0 - Não 1 - Sim

c) Indicadores de Desenvolvimento Ambiental (IDA)

IDA 1. Que prática de conservação é utilizada?

0 - Nenhuma prática é utilizada; 1 - São utilizadas práticas mecânicas;

2 - São utilizadas práticas biológicas.

IDA 2. Qual método de controle de pragas é adotado na unidade produtiva?

0 - Agrotóxicos; 1 - Nenhum método; 2 - Biológicos.

IDA 3. Quantos tipos de agrotóxicos são utilizados?

2 - (Nenhum); 1 - ( 1 produto); 0 - (2 ou mais produtos)

IDA 4. Há utilização de queimadas em suas atividades agropecuárias?

0 - Sim 1 - Não

IDA 5. Que destino é dado aos restos da produção?

0 - É queimado; 1 - É vendido/Serve de alimento para animais;

2 - É incorporado ao solo após a colheita.

IDA 6. É feito plantio de árvores objetivando a conservação do solo?

0 - Não 1 - Sim

IDA 7. Existe alguma área de reserva de mata nativa na propriedade?

0 - Não 1 - Sim

IDA 8. A residência possui algum sistema de esgoto ou tipo de fossa?

0 - Não 1 - Sim

IDA 9. É feita a rotação de terras?

0 - Não 1 - Sim

IDA 10. Se necessário, faz calagem?

0 - Não 1 - Sim

IDA 11. É feita a análise do solo?

0 - Não 1 - Sim

IDA 12. Faz adubação verde?

0 - Não 1 - Sim

IDA 13. Faz uso de material orgânico? 0 - Não 1 - Sim

IDA 14. Faz uso do solo de acordo com a sua vocação?

0 - Não 1 - Sim d) Indicadores de Desenvolvimento Político Institucionais - (IPI) (0 - Não 1 - Sim)

IPI 1. Você recebeu assistência técnica pública?

IPI 2. Você recebeu crédito de instituição pública?

IPI 3. Você recebeu algum produto ou serviço da secretaria de agricultura municipal ou estadual?

IPI 4. Participou de algum programa ou curso de capacitação do poder público?

\section{Germano Silva Maia}

Economista

Mestre em Economia Rural pela Universidade Federal do Ceará (UFC)

E-mail: germanomaia@hotmail.com

\section{Ahmad Saeed Khan}

Engenheiro Agrônomo

Doutor em Economia Agrícola e Recursos Naturais pelo Oregon State University.

Professor da Universidade Federal do Ceará (UFC)

E-mail: saeed@ufc.br

Patrícia Verônica Pinheiro Sales Lima

Engenheira Agrônoma

Doutora em Economia Aplicada pela Universidade de São Paulo (USP)

Professora da Universidade Federal do Ceará (UFC)

E-mail: pvpslima@gmail.com

Universidade Federal do Ceará (UFC)

Av. da Universidade, 2853 - Benfica, Fortaleza - CE CEP 60020-181 